\title{
8x8 Ağır Hizmet Aracı Fren Sistemi Tasarım, Hesaplama ve Uygulama Örneği
}

\section{Design, Calculation and Application Example of 8x8 Heavy- Duty Brake System}

\author{
Yiğit Vatansever $1^{*}\left(\mathbb{0}\right.$, N. Sefa Kuralay ${ }^{2}$, M. Umut Karaoğlan ${ }^{3 \oplus}$ \\ ${ }^{1}$ Dokuz Eylül Üniversitesi, Fen Bilimleri Enstitüsü, 35397, İzmir, TÜRKIYE \\ 2,3 Dokuz Eylül Üniversitesi, Mühendislik Fakültesi, Makina Mühendisliği Bölümü, 35397, İzmir, TÜRKIYE \\ Sorumlu Yazar / Corresponding Author*: yigit.vatansever@outlook.com.tr \\ Geliş Tarihi / Received: 12.09.2018 DOI:10.21205/deufmd.2019216225 \\ Kabul Tarihi / Accepted: 26.03.2019 Araştırma Makalesi/Research Article
}

Atıf șekli/How to cite: VATANSEVER, Y., KURALAY, N. S., KARAOĞLAN, M. U. (2019). 8x8 Ağır Hizmet Aracı Fren Sistemi Tasarım, Hesaplama ve Uygulama Örneği. DEUFMD, 21(62), 621-632.

Öz

Ağır hizmet araçları günümüzde birçok alanda ve farklı amaçlara yönelik olarak kullanılmaktadır. Bu çalışmada, özel amaçlı bir ağır hizmet aracının, standartlarca belirlenmiş performans gereksinimlerini sağlamak amacıyla havalı fren sistemine ait elemanların boyutlandırılması ve araç üzerine yerleşimini kapsayan bir hesaplama ve uygulama örneği sunulmuştur. Bu hesaplamalarda 4 akslı araç, fren sistemi hesaplarını basitleştirmek amacıyla 2 akslı olarak düşünülmüş ve talep edilen maksimum frenleme ivmesine göre fren sistemi yapı elemanları boyutları belirlenmiștir. Yapılan hesaplamalar sonucunda, taşıtın ön iki aksında iki kaliperli, arka iki aksında bir kaliperli disk fren kullanılmıștır.

Anahtar Kelimeler: Ağır Hizmet Aracı, Fren Sistemi Tasarımı, Havalı Fren

\begin{abstract}
Heavy-Duty vehicles are used in many fields for many purposes recently. In this study, calculation and application example is presented consist of capacity determination of air brake system of the special purpose heavy-duty vehicle to reach performance requirements in related standard procedures and layout of components into the vehicle body. The vehicle that has 4 axles is considered as if it has 2 axle for simplification of the brake system calculations and brake system components are determined according to maximum braking acceleration demand. As a consequence of the calculations, disc brake with two calipers in two front axles and disc brake with one caliper two rear axles are used in the vehicle.
\end{abstract}

Keywords: Heavy-Duty Vehicle, Brake System Design, Air brake

\section{Giriş}

Ağır hizmet taşıtları sıklıkla nakliye, savunma ve itfaiye araçlarında kullanılmaktadır. Son yıllarda teknolojinin hızla gelişmesinin de etkisi ile ağır hizmet taşıtları da ilgili çalışma koşulları için özelleştirilerek daha verimli, güvenli ve yüksek teknoloji içeren tașıtlara dönüşmüștür. Havaalanları gibi yüzölçümü olarak büyük ve yüksek risk barındıran bölgelerde alışılagelmişin dışında itfaiye araçlarına ihtiyaç vardır. $\mathrm{Bu}$ taşitlar geleneksel ticari kamyonlardan hem boyutsal olarak hem de içerdiği yapı elemanları 


\section{DEU FMD 21(62), 621-632, 2019}

bakımından çok farklıdır. Ayrıca, Sivil havacılık standartları uyarınca havaalanları çeşitli kategorilere ayrılmıştır. Gereken emniyetin sağlanması için de ayrılan bu kategorilere uygun şekilde, öngörülmüş sayıda ve kapasitede itfaiye aracı bulundurması gerekir. Bu özel taşıtlar ARFF (Aircraft Rescue and Fire Fighting) ismiyle anılır ve Ulusal Yangın Koruma Derneği (National Fire Protection Association) tarafından belirlenmiş NFPA-414 standardına uygun üretilmesi gerekmektedir.

Söz konusu tașit, tahrik edilebilir 8 adet aksa sahip (8x8), toplamda 52 Ton tașıma kapasiteli, 0-80 $\mathrm{km} / \mathrm{h}$ hıza 21 saniyede ulaşabilen, maksimum hızı $135 \mathrm{~km} / \mathrm{h}$ ile sınırlandırılmıș ve \% 60 eğime kadar tırmanabilen hem arazi hem de yüksek hız koşullarına uygun bir ağır hizmet taşıtıdır. Aracın genel görünümü Şekil 1'de gösterilmiştir. En büyük ayırt edici özelliği olarak ise iki adet güç tahrik sistemi barındırmasıdır. Tașıt iki adet commonrail dizel enjeksiyonlu turboşarjlı $425 \mathrm{~kW}$ gücünde 6 silindirli Euro 6 emisyon sınıfında motora sahiptir. $\mathrm{Bu}$ motorların ürettiği güç tork konvertörlü 7 ileri vitesli intarder ile donatılmış bir tam otomatik vites kutusuna aktarılmaktadır. Ayrıca her iklim koşulunda kesintisiz çalıșabilecek ağır hizmet tipi özel tasarım soğutma sistemine sahiptir. İki adet motor-vites kutusu çiftinden gelen güç ve tork, tekerleklere iletilmeden önce bir toplama kutusunda birleştirilmektedir Taşıtın tüm akslardan tahrik edilebilir olması nedeniyle toplama kutusundan çıkan tahrik bir transfer kutusu yardımıyla hem ön hem de arka akslara iletilir. Bu tahrik gücü akslardaki diferansiyel dişlileri ve tekerlek redüksiyonlarından geçtikten sonra taşıtı hareket ettirmek üzere lastik tekerleklere iletilir. Taşıtın güç tahrik sistemi şasinin en arka kısmına konumlandırılmıştır. Güç tahrik sisteminin hemen önünde dakikada 10000 Litre su köpük solüsyonu işleyebilen bir santrifüj pompa bulunmaktadır. Pompanın önünde ihtiyacı olan su ve köpügü sağlamak için 12500 Litre su, 1500 litre yangın söndürücü köpük kapasiteli polipropilen hammaddeden imal edilmiş bir tank bulunmaktadır.

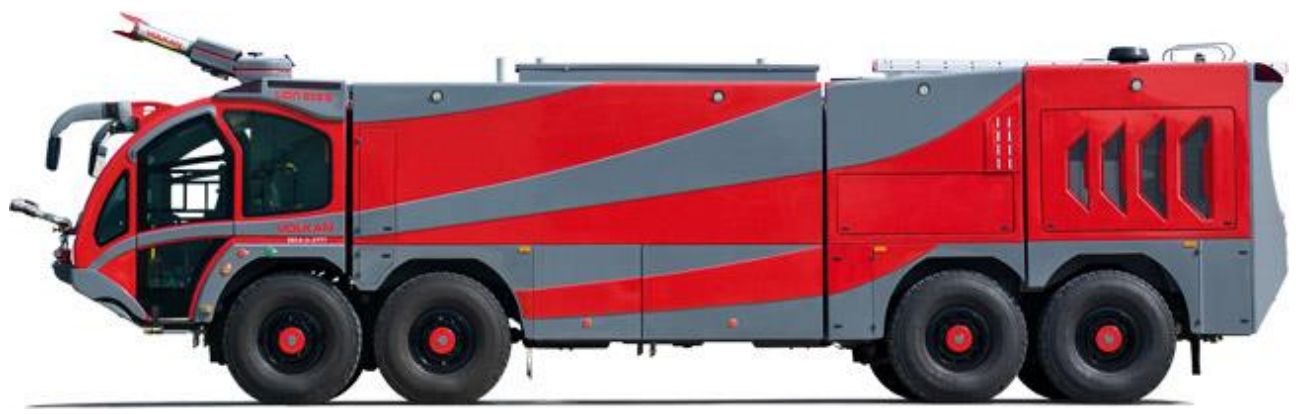

Şekil 1. 8x8 Ağır hizmet aracı genel görünümü

Ağır taşıt fren sisteminde genellikle iç fren faktörünün (balata ile tambur veya diskin sürtünmesiyle meydana gelen çevresel kuvvetin pabuçları açmaya çalışan kuvvete oranı) yüksek olması sebebiyle tambur frenler kullanımı tercih edilmektedir $[1,2,3]$. Fakat tambur frenlerin, frenleme ile oluşan isı sonucu balata sürtünme katsayısının ani düşüşü gibi temel olumsuz yönleri nedeniyle ağır taşıtlarda disk fren kullanımı gittikçe yaygınlaşmaktadır. Bayrakçeken ve Altıparmak [4], taşıtlarda fren kuvveti analizi için, yol tekerlek arası kuvvet bağıntı değerine ve lastik tipine göre değișen bir matematik model geliştirerek taşıtta elde edilebilecek maksimum fren kuvvetini belirlemişlerdir. Xu ve diğerleri [5], iki akslı bir araçta maksimum fren kuvvetinin belirlenmesi için dinamik frenleme modeli içerisinde yer alan parametreleri en uygun değerlerini bir optimizasyon yöntemiyle belirlemiștir. İki akslı taşıtların dişında ekli taşıtlarda de fren kuvveti dağılımının belirlenmesi için yapılmıș çalıșmalar literatürde mevcuttur [6]. Belirlenen çalışma koșuluna göre havalı fren sisteminde yer alan elemanların analizi He ve diğerleri [7] tarafından gerçekleștirilmiştir. Havalı fren kullanan taşitlarda disk ve tambur fren tercihinin mukayesesi Mithun ve diğerleri [8] tarafından incelenmiștir. Bu çalıșma sonucunda disk fren ile elde edilen frenleme torkunun tambur fren ile elde edilen değere göre daha yüksek olduğu görülmüştür.

$\mathrm{Bu}$ çalışma kapsamında, literatürde incelenen çalıșmalardan farklı olarak, tahrik edilebilir dört 
DEU FMD 21(62), 621-632, 2019

aksa sahip bir ağır tașıt, efektif aks aralığı hesabı ile iki akslı olarak ele alınarak araçta elde edilebilecek maksimum fren kuvveti hesaplanmıştır. Bu değere göre fren sistemi yapı elemanlarının boyutları ve fren disklerinde kullanılacak fren kaliperi sayısı belirlenmiștir. Hesaplanan değerlere göre tüm fren sistemi elemanları araç üzerine yerleștirilmiștir.

\section{Fren sistemi tasarım esasları}

$\mathrm{Bu}$ çalışmada, dört akslı ve tüm akslarından tahrikli bir taşıta ait havalı fren sisteminin taşı dinamiğine etkisi incelenmiştir. Kullanılan matematiksel model yardımıyla, ARFF tașıtlarının tabi olduğu NFPA-414 standardında öngörülen koşulları sağlayacak çeşitli frenleme ivmeleri tespit edilmiş ve bu ivme değerleri için indirgenmiș aks yükleri elde edilmiștir. Elde edilen veriler ışığında taşıtın gereksinimi olan fren sistemi konstrükiyonu, fren sisteminin yapı elemanları, sürekli yavaşlatıcı tipi ve kapasitesi bilgisayar destekli olarak tasarlanmıștır. Çalışmaya konu taşıtın tabi olduğu Uçak Kurtarma ve Yangın ile Mücadele Standardı NFPA-414'de belirtilen frenleme koșulları ve diğer performans kriterleri tablo 1'de belirtilmiştir.

Tablo 1. NFPA-414 ARFF tașitları performans kriterleri.

\begin{tabular}{|c|c|}
\hline $\begin{array}{l}\text { Performans } \\
\text { Parametreleri }\end{array}$ & $\begin{array}{c}\text { Taşıtın Su Tankı } \\
\text { Kapasitesi: >6000 L }\end{array}$ \\
\hline Son hiz $(\mathrm{km} / \mathrm{h})$ & $\geq 113$ \\
\hline $\begin{array}{l}\text { Servis freni ile } \\
\text { durma mesafesi (m); } \\
33 \mathrm{~km} / \mathrm{h} \text { 'dan 0'a } \\
64 \mathrm{~km} / \mathrm{h} \text { 'dan 0'a }\end{array}$ & $\begin{array}{l}\leq 12 \\
\leq 49\end{array}$ \\
\hline 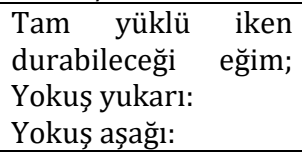 & $\begin{array}{l}\leq \% 50 \\
\leq \% 50\end{array}$ \\
\hline $\begin{array}{l}64 \mathrm{~km} / \mathrm{h} \text { hizdan } \\
\text { imdat freni ile durma } \\
\text { mesafesi }(\mathrm{m})\end{array}$ & $\leq 88$ \\
\hline $\begin{array}{l}\text { Park frenleri ile } \\
\text { durabileceği } \\
\text { Yokus yum; yukarı: } \\
\text { Yokuş aşağı: }\end{array}$ & $\begin{array}{l}\leq \% 20 \\
\leq \% 20\end{array}$ \\
\hline
\end{tabular}

NFPA-414 standardı, uçak kurtarma ve yangınla mücadele (ARFF) taşıtlarının yangınla mücadele ve yolcuları kurtarma operasyonlarını yürütmek, gerek duyulan donanım ve personel taşıma görevini yerine getirmek için ihtiyaç duyulan tasarım, performans ve kabul ölçütlerini belirleyen, sivil havacilıktaki tek standarttır.

Standart; taşıtları, taşıyabilecekleri su-köpük kapasitesine göre sınıflandırır. Bunun nedeni ise ICAO (International Civil Aviation Organization) kuruluşunun havaalanlarını çeșitli kategorilere ayırmasıdır. $\mathrm{Bu}$ kategoriler doğrudan havaalanına iniş-kalkış yapabilecek uçak tiplerini ve ilgili kategoriye ait havaalanının bulundurması gereken en düşük su köpük karıșımı miktarını belirler. Bu nedenle NFPA414 standardı, taşıtın ağırlığının ve dıș ölçülerinin açıklaması ile başlar. Motor ve elektrik sistemi ile devam eder. Taşıtın taşıyabileceği su-köpük karışımı miktarı, taşıtın ağırlığını aynı zamanda kaç akslı olması gerektiğini ortaya çıkarmış olur.

Standart gereği taşıt kaç akslı olursa olsun muhakkak tüm aksları tahrikli olmalıdır. Bunların ardından süspansiyon sistemi, jant ve lastikler, çeki bağlantıları, fren sistemi ve yönlendirme sistemi ile ilgili gereklilikleri açıklar. Tașıtın yapı elemanlarına ait açıklamaların ardından, personel taşıyan kabin, dış gövde, yangın söndürme sistemi; yangın pompası ve pompa tahriki, su-köpük tankı ve köpük sistemi gereklilikleri ile devam eder. Suköpük karıșımı detayları, nozullar, çatı ve tampon monitörleri, araç altı söndürme nozulları, kuru kimyevi toz sistemi, yangın çıkrıkları ve aydınlatma-elektrik donanımı ile sonlanir.

\section{Taşıt özellikleri}

Aks yükleri dağılımında ise NFPA-414 standardında belirtildiği gibi; akslar arasındaki en büyük aks yükü farkı \%10, aynı aks üzerindeki tekerlekler arasındaki en büyük yük farkı ise $\% \quad 5^{\prime} \mathrm{i}$ geçmemesi prensibi uygulanmıştır.

Üst yapı bileșenleri bu dağılıma uygun olarak, su ve köpük tankı aksların tam ortasında, santrifüj pompa ve tesisatı su ve köpük tankının arkasına, personel kabini en ön kısma, kuru kimyevi toz tankl ise kabinin hemen arkasına konumlandırılmıştır. Taşıt ağırlığını oluşturan bileşenler Tablo 2'de verilmiştir. 
DEU FMD 21(62), 621-632, 2019

Tablo 2. Üst yapı bileşenlerine ait kütle ve konum değerleri

\begin{tabular}{lc} 
Bölüm & Kütle $[\mathrm{kg}]$ \\
\hline Motor Bölümü & 1050 \\
Pompa Bölümü & 1870 \\
Üstyapı Hariç Şasi & 20600 \\
Su Tankı Bölümü & 17800 \\
Ön Modül Bölümü & 1000 \\
Kabin Bölümü & 2940 \\
\hline
\end{tabular}

Taşıtın her bir aksı 13000 kg taşıma kapasitesine sahip dört aksı sayesinde $52000 \mathrm{~kg}$ bir kapasiteye sahiptir. Ancak çalıșmaya konu olan versiyonu ise $46000 \mathrm{~kg}$ yük için tasarlanmış bir modeldir.

\section{Fren sistemi hesaplamaları}

Fren sistemi dinamik davranıșı ve fren performansının belirlenebilmesi için taşıtı iki akslı bir taşıt modeline indirgeme yöntemi geliştirilmiştir. Bunun için etkin aks açıklığı olarak ifade edilen bir matematiksel eşitlik geliștirilmiștir. Etkin aks açıklığı, öncelikle aks yükü hesap cetvelini kullanarak ön ve arka aks gruplarının merkezlerini tespit eder. Ön aks grubunun kendi içindeki merkezi ile arka aks grubunun kendi içindeki merkezi arasındaki uzaklık etkin aks açıklığı olarak isimlendirilmiștir. Her bir frenleme ivmesi değeri için tașıtın hesaplanabilen bir etkin aks açıklığı değeri bulunmaktadır. Hesaplamaların tamamında olduğu gibi taşıtın birinci aksının merkezini başlangıç noktası kabul edip, birinci ve ikinci aks için hesaplanan dinamik aks yüklerini kullanarak bir kuvvet dengesi eșitliği yazılır. Birinci ve ikinci aksın olușturduğu ön aks grubunun kütle merkezi L2 uzaklığından daha kısa, birinci ve ikinci aks arasında bulunan bir mesafedir. Bu mesafe ön aks merkezini sabit mesnet kabul eden bir kuvvet - moment dengesi eșitliği ile elde edilir. İkinci aksın aks yükünün, birinci aks merkezine göre moment hesabı L2.m2 ifadesini olușturur. Ön aks grubu kütle merkezinin birinci aksın merkezine olan uzaklığı ve iki aksın kütleleri toplamının birbiri ile çarpımı ise ön aks grubu yüklerinin birinci aksa göre moment ifadesini oluşturur. Ön aks grubu kütle merkezinin birinci aks merkezine olan uzaklığ $\breve{l}_{1} \mathrm{~L}_{2} \cdot \mathrm{m}_{2}$ ifadesinin $\mathrm{m}_{1}+\mathrm{m}_{2}$ ifadesine $L_{E}=\left(L_{2}-\left(\frac{L_{2} \cdot m_{2}}{m_{1}+m_{2}}\right)\right)+\left(L_{4}-\left(\frac{L_{2} \cdot m_{3}}{m_{3}+m_{4}}\right)\right)+L_{3}$ bölünmesi ile elde edilir. Bu etkin aks açıklığ matematiksel ifadesinin ilk terimini oluşturur. Aynı eşitlikler üçüncü aksı mesnet noktası alarak oluşturulduğunda arka aks grubuna ait değerler elde edilebilir.Benzer șekilde arka aks grubu içinse, üçüncü ve dördüncü aksın hesaplanan dinamik aks yüklerini kullanarak bir kuvvet dengesi eșitliği oluşturulduğunda etkin aks açıklığı ifadesinin ikinci terimi elde edilmiş olur. İfadenin son terimi ise sabit olarak bulunan, tașıtın ikinci ve üçüncü aksları arası uzaklıktır. $\mathrm{Bu}$ üç terimin toplamından etkin aks açıklı̆̆ değeri elde edilir. İfade hem sabit hem de değişken terimler içerdiği için farklı fren ivmesi değerleri için farklı aks açıklığı uzaklık değerleri oluşturur. Dinamik aks yükleri ile fren dinamiğine ait hesaplamaların içerisinde daima etkin aks açıklığı ifadesi parametrik olarak ilişkilendirilmiştir. Ana nedeni ise, bu değer neticesinde ön ve arka aks gruplarının kütle merkezine göre uzaklığını tespit etmesidir. Etkin aks açıklığı ifadesinin sırasıyla birinci ve üçüncü terimi ön ve arka aks gruplarının kütle merkezine göre uzaklığının belirlenmesinde de kullanılır. Aks gruplarının kütle merkezine göre uzaklığı ise fren dinamiği için kullanılan dinamik aks yükleri değerleri ile doğrudan ilişkili olduğu için taşıtın frenleme davranıșını ve frenleme oranını etkiler.

Fren davranıșı fren kuvvetlerinin ön ve arka aksa dağılımına bağlıdır. Fren kuvveti dağılımı tasarımın en önemli ölçütüdür. Aşağıdaki şekilde fren ivmesine bağlı etkin aks açıklığı değișimi gösterilmektedir. Etkin aks açılı̆ğg ifadesinde yer alan; $m_{1} m_{2} m_{3} m_{4}$ değerleri sırasıyla, birinci, ikinci, üçüncü ve dördüncü aksların aks yükleri değerleridir. $\mathrm{L}_{2}$ değeri ikinci aksın başlangıç noktasına olan uzaklığını, $\mathrm{L}_{3}$ değeri üçüncü aksın ikinci aksa olan uzaklığını, L4 değeri ise dördüncü aksın üçüncü aksa olan uzaklığını belirtir. Etkin aks açıklığı ifadesi aşağıdaki formül ile hesaplanmaktadır. Etkin aks açıklığında bulunan aks yükü kütle değerleri frenleme ivmesine bağlı olarak dinamik aks yükü değișeceği için ivme ile değișmektedir. Bu nedenle Denklem 1'e göre hesaplanan etkin aks açıklığı değerinin çeşitli frenleme ivme değerleri için değişimi Şekil 2'de gösterilmiştir. 


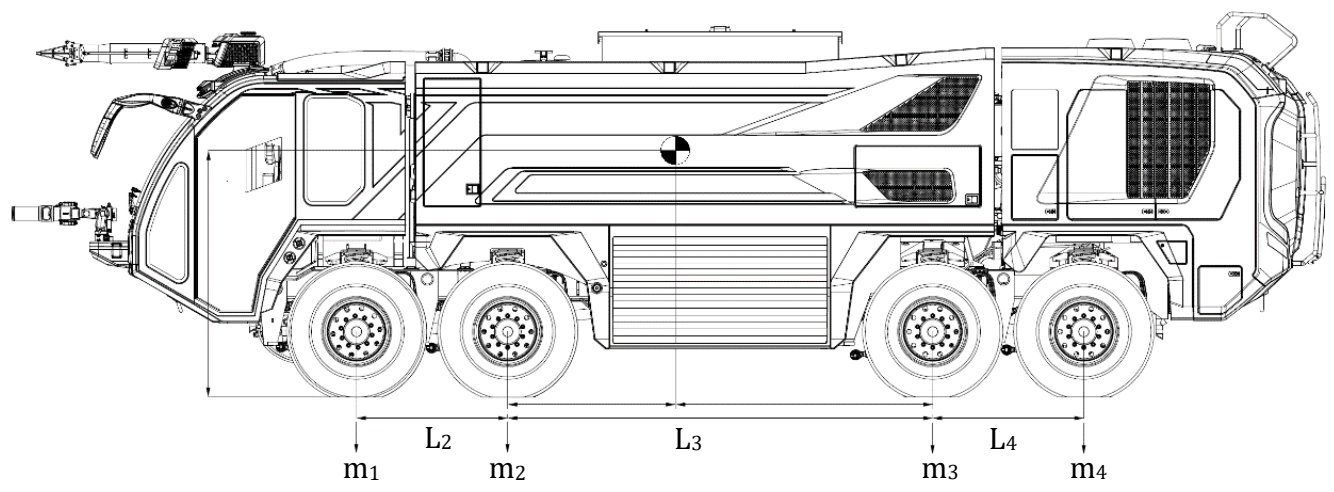

Şekil 2. Etkin aks açıklığı ifadesindeki geometrik ölçülerin gösterimi

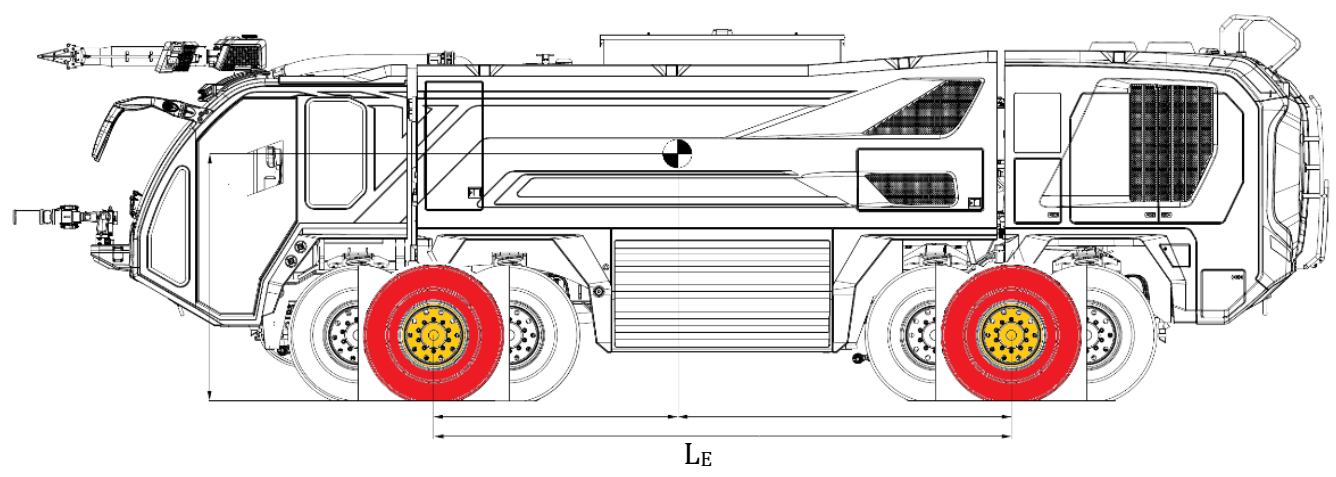

Şekil 3. Etkin aks açıklı̆̆ı geometrik ölçüsünün gösterimi

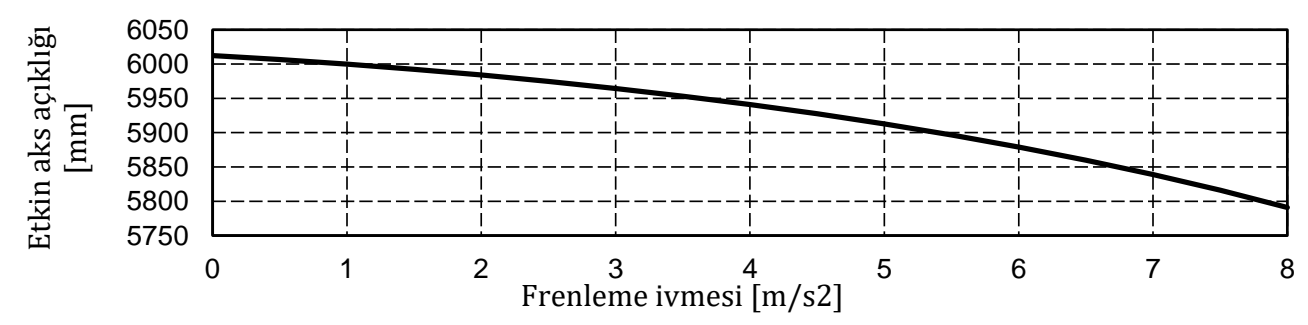

Şekil 4. Etkin aks açıklığının frenleme ivmesine göre değişimi.

Etkin aks açıklığı değerinin belirlenmesinden sonra, ön ve arka aks gruplarının kütle merkezine olan uzaklıklarının da belirlenmesi gerekmektedir. $\mathrm{Bu}$ nedenle tıpkı etkin aks açıklığı ifadesinde kullanılan eșitlikler gibi, ön ve arka aks grupları için de kuvvet dengesi eşitlikleri kullanılarak aks gruplarının kütle merkezine göre uzaklıkları belirlenir. $\mathrm{Bu}$ eşitliklerde $\mathrm{X}_{\mathrm{G}}$ kütle merkezinin başlangıç noktasına göre uzaklığıdır. Ön ve arka aks gruplarının kütle merkezine olan uzaklıkları sırası ile aşağıda belirtilmiştir. 
DEU FMD 21(62), 621-632, 2019

$$
\begin{aligned}
& L_{V}=-x_{G}-\left(\frac{L_{2} \cdot m_{2}}{m_{1}+m_{2}}\right) \\
& L_{H}=L_{2}+L_{3}+L_{4}-\left(\frac{L_{4} \cdot m_{3}}{m_{3}+m_{4}}\right)+x_{G}
\end{aligned}
$$

Ön ve arka aks gruplarının kütle merkezine olan uzaklıklarını belirten ifadeler elde edildikten sonra, frenleme durumunda, ön ve arka aks gruplarında oluşan dinamik aks yükleri belirlenebilir. Dinamik aks yükleri ifadesi de belirli bir noktaya göre kuvvet dengesi eșitliğinden türetilmiş eşitliklerdir.

$\mathrm{Bu}$ ifadelerde bulunan G; taşıtın ağırlığını, LV ön aks grubunun kütle merkezine olan uzaklığını, $\mathrm{L}_{H}$ arka aks grubunun kütle merkezine olan uzaklığını, LE etkin aks açıklığı değerini, h kütle merkezinin yer düzlemine dik uzaklığını, z ise frenleme ivmesinin yerçekimi ivmesine oranı olan frenleme oranını ifade eder. Așağıdaki 4 ve 5 numaralı eşitliklerde sırasıyla ön ve arka aks gruplarına ait dinamik aks yükü eşitliği verilmiştir.

$$
\begin{aligned}
& G_{V}=G \cdot\left(\frac{L_{H}}{L_{E}}+z \cdot \frac{h}{L_{E}}\right) \\
& G_{H}=G \cdot\left(\frac{L_{V}}{L_{E}}-z \cdot \frac{h}{L_{E}}\right)
\end{aligned}
$$

Taşıtın dinamik davranışı ele alındığında, herhangi bir iz değiştirmeden, savrulmadan veya tekerlek - yol teması yitirilmeden fren yapabiliyor olması gerekmektedir. Bu nedenle fren sistemindeki en önemli tasarım ölçütü fren kuvveti dağılımıdır. Frenleme oranına ve tașıtın yük durumuna göre fren kuvveti dağılım oranı değişiklik gösterir. Fren kuvveti dağılımı eşitliği aşağıda belirtilmiştir.

$$
K=L_{H}+\frac{z \cdot h}{L_{V}-z \cdot h}
$$

Frenleme oranı ve dinamik aks yükünün çarpımı ile aks gruplarında oluşması gereken fren kuvvetleri elde edilir. Akslarda bulunan tüm tekerlekler eş olduğu için aks grubunda gerekli olan fren kuvveti ile tekerlek sayısı arasında doğru bir orantı vardır.

İdeal frenleme durumu ele alındığında ise, taşıtın ön ya da arka aks grubunun tekerlek-yol temasının kesilme sınırları belirlenir. Çeşitli frenleme oranları için, ideal frenleme durumu gerekli olan fren kuvvetinin taşıt ağırlığına bölünmesi ile elde edilir. Arka aks grubunun fren kuvvetinin taşıt ağırlığına göre oranı sıfır olduğunda taşıtın arka aksları dengeli halden çıkar ve taşıt savrulur. İdeal fren kuvveti dağılımı Şekil 3'de gösterilmiştir. Ön ve arka akslarda olușan ideal fren kuvveti dağılımı aşağıdaki 7 ve 8 numaralı denklemlerde belirtilmiştir.

$$
B_{V} /_{G}=z^{2} \cdot \frac{h}{L_{E}}+z \frac{L_{H}}{L_{E}}
$$

$$
B_{H} /_{G}=-z^{2} \cdot \frac{h}{L_{E}}+z \frac{L_{V}}{L_{E}}
$$

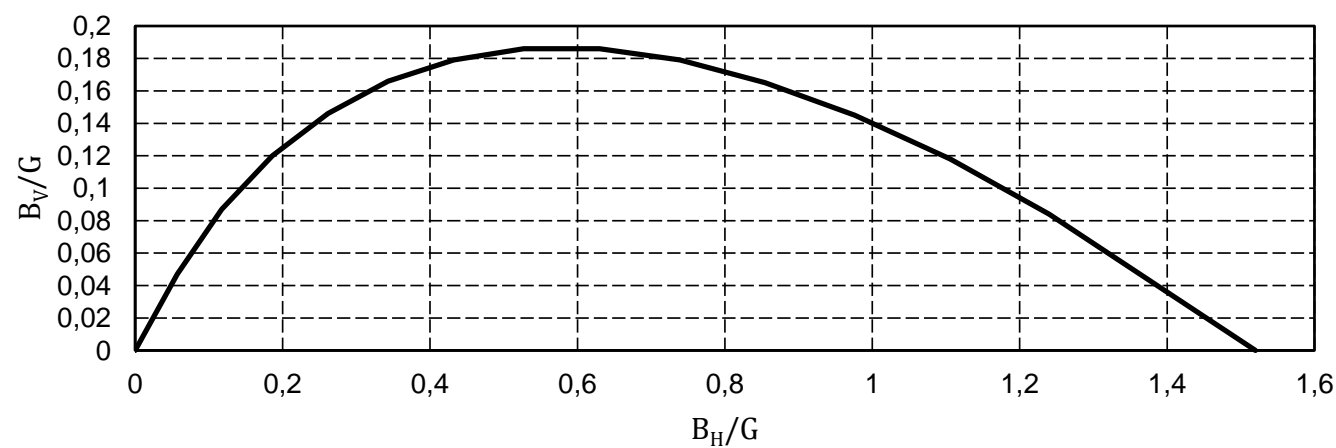

Şekil 5. İdeal fren kuvveti dağılımı. 


\section{Bulgular}

Frenleme durumunda ön ve arka aks gruplarına ait aks yükleri birbirine eşit olmayacağı için ön ve arka aks gruplarının tutunma sinırları da birbirinden farklı olur. Bu durumu incelemek için aşağıdaki eşitlikler ile ifade edilen; frenleme oranı ve yol-tekerlek arası sürtünme katsayısı ile bağlantılı elde edilen grafikten faydalanılır. $\mathrm{Bu}$ grafiğe eklenen $45^{\circ}$ eğik bir çizgi sayesinde hangi aksın hangi değerden itibaren yol tutunmasını yitirdiği tespit edilir.

$$
\begin{aligned}
& z_{H}=\frac{\mu \cdot L_{H}}{\frac{L_{F}}{K+1}} \\
& z_{V}=\frac{\mu \cdot L_{v}}{\frac{L_{F}}{1+\frac{1}{K}}}-\mu \cdot h
\end{aligned}
$$

Tüm bu veriler ıșığında, tașıt için öngörülen fren sistemine ait veriler aşağıda bulunan tabloda belirtilmiştir.

Tablo 3. Fren kaliperi özellikleri.

\begin{tabular}{lll} 
Tasarım Ölçütü & Değeri & Birimi \\
\hline Sürtünme yarıçapı & 0.1726 & $\mathrm{~m}$ \\
İç fren faktörü & 0.78 & - \\
Mekanik verim & 0.95 & - \\
Orta manivela oranı & 15.6 & - \\
Açılma kuvveti & 90 & $\mathrm{~N}$ \\
Uygulanan kuvvet & 12700 & $\mathrm{~N}$ \\
\hline
\end{tabular}

Tablodaki veriler ışığında fren kaliperine uygulanan kuvvet doğrultusunda elde edilebilecek moment değeri ifadesi aşağıdaki eşitlik ile gösterilmiştir. İfadede yer alan Fc; Fren körüğünden uygulanan kuvvet, rm; fren diskinin sürtünme yarıçapı, $C^{*}$; iç fren faktörü, $\eta m$; mekanik verim, im; orta manivela oranı, F0 ise açılma kuvveti değerleridir.

$$
M_{B}=\left(\left(F_{C}-F_{0}\right) \cdot C^{*} \cdot \eta_{m} \cdot i_{m}\right) \cdot r_{m}
$$

Taşıt üzerinde kullanılması öngörülen fren bileşenlerine ait boyutlandırma ve kontrol aşağıda ifade edilen şekilde ve belirtilen formüller ile sağlanmıștır. Bu bileșenlerin tümü endüstride bulunan en yüksek kapasiteli ürünlerdir. $\mathrm{Bu}$ ürünlerin yeterliliği ilerleyen kısımlarda sözü edilen denklem ve değerler ile kontrol edilmiştir. Denklem 12 de bulunan $F_{C}$ fren körügü kuvveti, körüğe uygulanan basınç değerine göre değişkenlik gösterebilmektedir. Ön ve arka aks gruplarında bulunan fren körükleri körük hacmi olarak aynı hacme sahip olup arka akslardaki fren körüklerinin acil durum fren sistemi eklentisi nedeniyle ilave bir yaylı mekanizma barındırdığı için ön fren körüklerinden dış ölçüler olarak daha büyüktür. Uygulanan hava basıncına göre fren körügünde oluşan kuvvetin değişimi aşağıdaki grafikte gösterilmiştir ve 12 numaralı eșitlik ile elde edilmiştir. Eşitlikte yer alan $\mathrm{p}_{\mathrm{A}}$ ifadesi fren sistemindeki havanın işletme basıncı, $r_{c}$ körüğün içinde bulunan silindirin yarıçapı, Fc ise körükte oluşan fren kuvvetidir.

Fren diski boyutlandırması incelenecek olursa temel kısıtlayıcı etmen jant çapı olarak görülmektedir. Taşıtta kullanılan jantların iç çapı nedeniyle kullanılabilecek en yüksek fren diski çapı 450 mm'dir. Bu çalışmada öngörülen fren sisteminde bulunan disk çapı ise $434 \mathrm{~mm}$ 'dir.

$\mathrm{Bu}$ fren disklerine montaj edilebilecek kaliperlerde iki adet piston bulunmalıdır ve bu pistonlar bir manivela ile körük kuvveti arttırılarak hareket ettirilmelidir. Denklem 4 ve 5 'in taşıt ağırlığı ile çarpılması halinde oluşan Denklem 13 ve 14, frenleme durumu için ön veya arka aks gruplarında oluşması gereken frenleme kuvveti elde edilebilmektedir. Denklem 11 ve Denklem 12'nin kullanılmasiyla fren ekipmanlarının tekerlek üzerinde oluşturabileceği frenleme kuvvetine ulaşlabilir. Denklem 15'te tekerlekte oluşacak frenleme kuvvetinin matematiksel ifadesi verilmiștir. Ifadede yer alan $r_{\text {dyn: dinamik tekerlek }}$ yarıçapıdır. Uygulanabilecek en yüksek frenleme ivmesi için değerler Tablo 4'te verilmiștir. Tablo 4'teki değerler elde edilirken basınçlı hava sisteminin işletme basıncı değeri olan $\mathrm{p}_{\mathrm{A}}=10$ bar olarak alınmıştır.

$$
\begin{aligned}
& F_{C}=\pi \cdot\left(r_{C}\right)^{2} \cdot p_{A} \\
& B_{V}=G\left(z^{2} \cdot \frac{h}{L_{E}}+z \frac{L_{H}}{L_{E}}\right) \\
& B_{H}=G\left(-z^{2} \cdot \frac{h}{L_{E}}+z \frac{L_{V}}{L_{E}}\right) \\
& F_{B}=\frac{F_{c} \cdot i_{m} \cdot \eta_{m} \cdot C^{*} \cdot r_{m}}{r_{d y n}}
\end{aligned}
$$


Tablo 4. Fren bileșenleri hesaplama değerleri

\begin{tabular}{lll} 
Hesaplama ölçütü & Değeri & Birimi \\
\hline $\begin{array}{l}\mathrm{B}_{\mathrm{V}}-\text { Ön aks grubu fren } \\
\text { kuvveti }\end{array}$ & 256.6 & $\mathrm{kN}$ \\
$\begin{array}{l}\text { B }- \text { Arka aks grubu fren } \\
\text { kuvveti }\end{array}$ & 82.8 & $\mathrm{kN}$ \\
$\begin{array}{l}\text { Tekerlekte olușturulan } \\
\text { frenleme kuvveti }\end{array}$ & 34.7 & $\mathrm{kN}$ \\
\hline
\end{tabular}

$$
\begin{aligned}
& k_{C}=F_{C} / s_{C} \\
& k_{P}=F_{P} / s_{P} \\
& i_{m}=\frac{B_{V}}{8 \cdot F_{C} \cdot \eta_{m} \cdot C^{*} \cdot r_{m}}
\end{aligned}
$$

Tablo 4'te hesaplanan değerler ile görülmektedir ki, taşıtın ön aks grubunda bulunan tekerleklerin her biri için iki adet kaliper, taşıtın arka aks grubunda bulunan tekerleklerin her biri için ise bir adet kaliper gerekmektedir. Bu kaliperlerin kuvvet olușturmasını sağlayan fren körüğü ile ilgili ölçüler Şekil 6'da gösterilmektedir. Fren diskinde olduğu gibi, fren körüğü için de jant lastiğin akslara montajı kısıtlayıcı etmendir. Herhangi bir girișim olmaması için müsaade edilen en yüksek fren körügü çapı 150 mm'dir. Denklem 16'da fren körüğünün içinde bulunan geri getirme yayına ait katılık formülü bulunmaktadır. Denklem 17'de ise fren kaliperi içerisinde bulunan kaliper pistonlarının geri getirme yayı katılık formülü bulunmaktadır. Gereken en yüksek manivela oranı Denklem 15 ile elde edilebilir. Denklemde yer alan 8 ifadesi, ön aks grubunda tekerlek bașına iki adet kaliper kullanılması kabulu ile elde edilmiștir. Tek kaliper kullanılması halinde manivela oranı
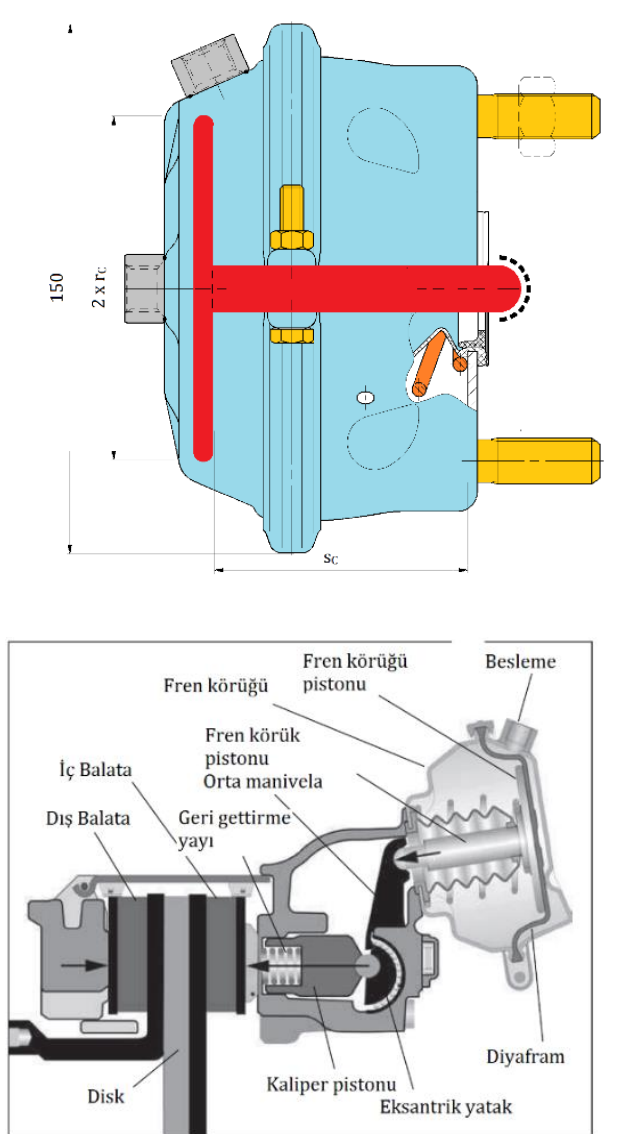

Şekil 6. Fren körük ve kaliper gösterimi.

konstrüktif olarak elde edilemeyecek kadar çok artmaktadır. Bu nedenle tekerlek başına iki kaliper ön kabulu ile hareket edilmiștir. Kullanılan diskin çapı ve jant bağlantı noktaları ele alındığında takılacak kaliper ölçü sınırları ve kaliperde bulunacak piston sayısı ve çapı da sınırlanarak elde edilmiş olur.

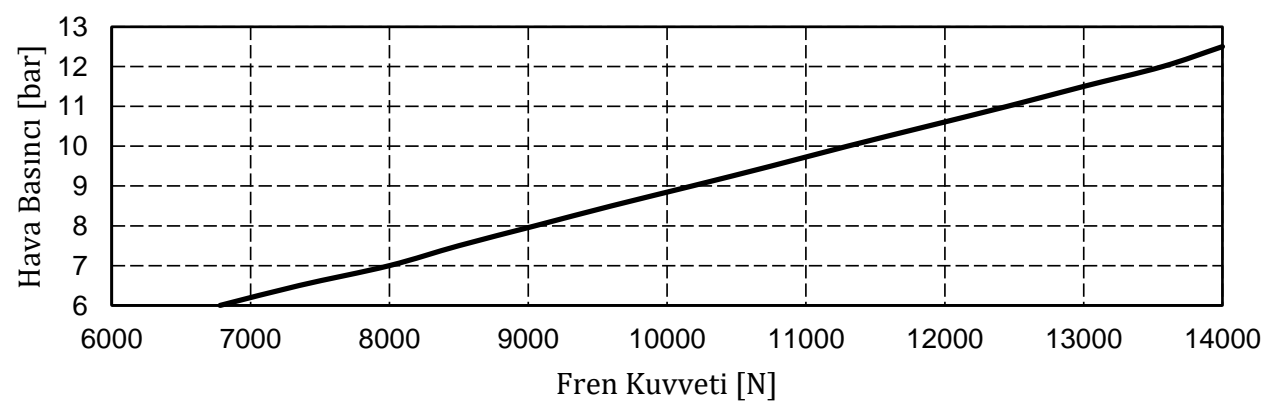

Şekil 7. Uygulanan hava basıncına göre fren kuvveti değișimi. 


\section{DEU FMD 21(62), 621-632, 2019}

Çalışmaya konu taşıtın tabi olduğu Uçak Kurtarma ve Yangın ile Mücadele Standardı NFPA-414'de belirtilen frenleme koşulları ve diğer performans kriterleri Tablo 1'de daha önce belirtilmiști. Tașıtın su tankı kapasitesi 14500 litre olduğu için >6000 litre sınıfına dahil olmaktadır. Tabloda belirtilen frenleme koşullarından hareketle frenleme ivmeleri tespit edilmiş, ön ve arka aks gruplarının yol-tekerlek arası sürtünme katsayısı ile frenleme oranı ilişkisi incelenip, hangi aksın hangi frenleme oranı değerinden itibaren bloke olduğu çeşitli grafikler ile gösterilmiștir.

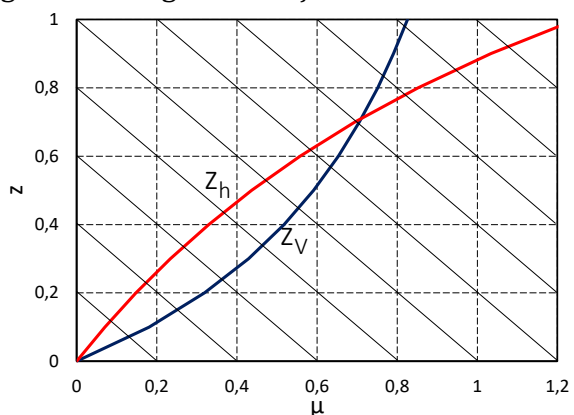

a)

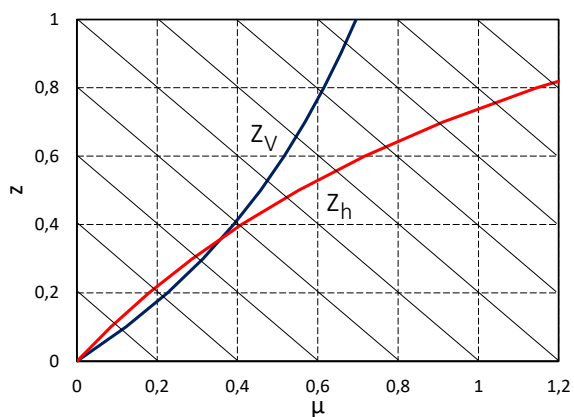

b)

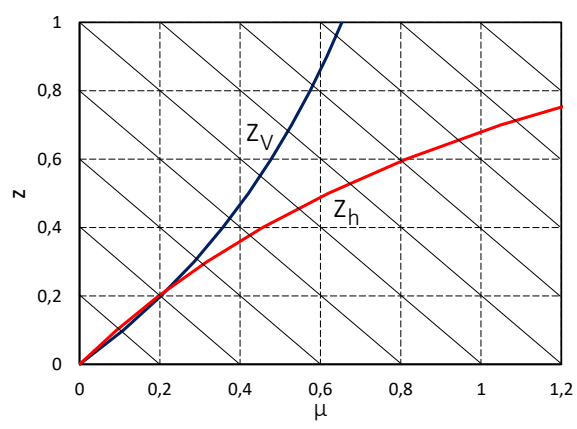

c)

Sekil 8. Ön ve arka aks gruplarının frenleme oranı - sürtünme katsayısı ilişkisi.
Denklem 7 ve 8'de kullanılan eşitliklerden hareket ile yukarıda gösterilen grafikler elde edilmiștir. Şekil 7.a 0,8 ivme oranı için gereken ivme değeri olan olan $7,85 \mathrm{~m} / \mathrm{s}^{2}$ değeri için olușturulmuștur. Șekil 7.b'de ise saatte $64 \mathrm{~km} \mathrm{hız}$ ile 49 metre mesafede durma koșulu için gereken ivme olan $3,2 \mathrm{~m} / \mathrm{s}^{2}$ değeri için oluşturulmuştur. Son olarak Şekil 7.c saatte 64 $\mathrm{km}$ hız ile acil durum frenleri kullanarak 49 metre mesafede durma koşulu için gerekli olan ivme $1,8 \mathrm{~m} / \mathrm{s}^{2}$ değerleri için oluşturulmuştur. $\mathrm{Bu}$ grafikler elde edilirken Denklem 1'de bulunan etkin aks açıklığı ifadesi kullanıldığı için, taşıt her frenleme ivmesi değerinde farkl bir aks açıklığına sahiptir. Buna bağlı olarak da ideal frenleme eğrileri her frenleme değeri için farklı bir grafik oluşturmaktadır. $\mathrm{Bu}$ grafikler sayesinde ön ya da arka aks gruplarından hangisinin frenleme ivmesine göre önce bloke olacağı tespit edilmiştir

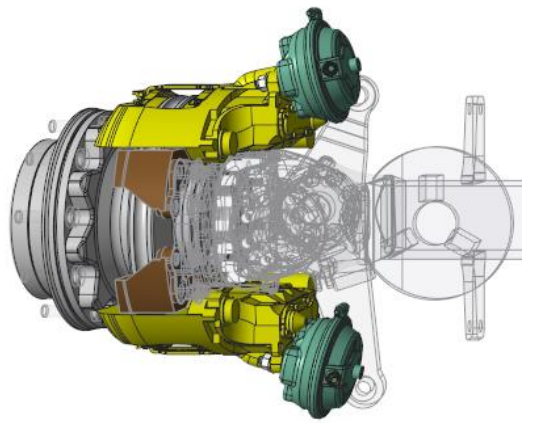

a)

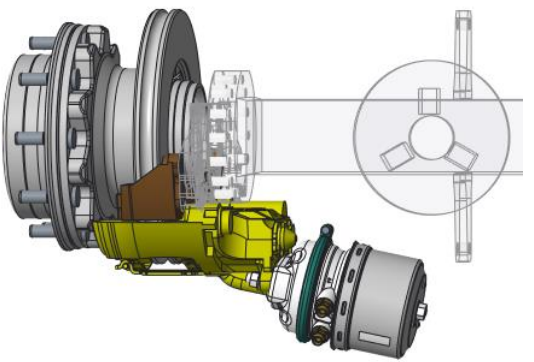

b)

Şekil 9. Birinci ve ikinci aks tekerlekleri fren donanımı (a) ile üçüncü ve dördüncü aks tekerlekleri fren donanımı (b). 
Tasarlanan ve öngörülen fren donanımı ile teçhiz edilen taşıt gerçek olarak ilgili standartta belirtilen testlere tabi tutulmuş ve tüm testlerden başarı ile geçmiştir. Şekil 10 ve Şekil 11'de bulunan grafiklerden de görülebileceği donatılan fren donanımı talep edilen yaklaşık $3.5 \mathrm{~m} / \mathrm{s} 2$ frenleme ivmesinin üzerine kolaylıkla çıkabildiği için standartlarda belirtilen mesafelerin yaklaşık olarak 1/3'ünde taşıtı kolaylıkla durdurabilmektedir. Grafiklerde bulunan yeşil renkli eğri taşıt yanal ivme ölçümü olduğu için 0 değerinde sabittir. Sarı renkli eğri taşıtın düşey hareketinin ivmesini gösterdiği için test süresince yerçekimine eşit seyretmiștir.

Ön ve arka akslarda bulunan fren donanımı sırasıyla Şekil 8'de gösterilmiştir. Frenleme ivmeleri ve aks yüklerine bağlı frenleme kuvvetleri göz önüne alındığında; Şekil 6'da gösterilen tasarım endüstride kullanılan en ağır tipteki fren donanımıdır. Buna rağmen ön aks grubu için gerekli olan frenleme kuvvetlerini tek başına karşılayamadığı için tașıtın ön akslarında tekerlek bașına iki adet tercih edilmiştir. Tüm fren donanımına ek olarak taşıtın vites kutularında hidrodinamik Retarder ve elektronik motor freni bulunmaktadır. Ön ve arka aks gruplarında aynı kuvvette pnömatik fren körüğü bulunmaktadır. Arka akslarda bulunan fren körükleri acil durum fren mekanizması ile teçhiz edildiği için körükleri öne klyasla daha uzundur. Belirlenen karakteristik parametreler ve elde edilen sonuçlar neticesinde fren sistemine ait tamamlayıcl yapı elemanları ve yan elemanların araç üzerine monte edilmesi ile fren sisteminintüm araç üzerinde gösterimi Şekil 9'da verilmiștir.

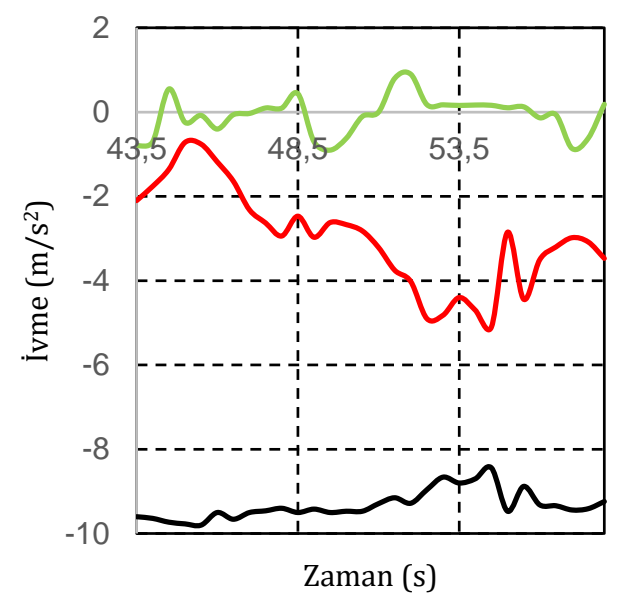

Şekil 10. $33 \mathrm{~km} / \mathrm{h}$ - 0km/h yavaşlama ivme ölçüm grafiği.

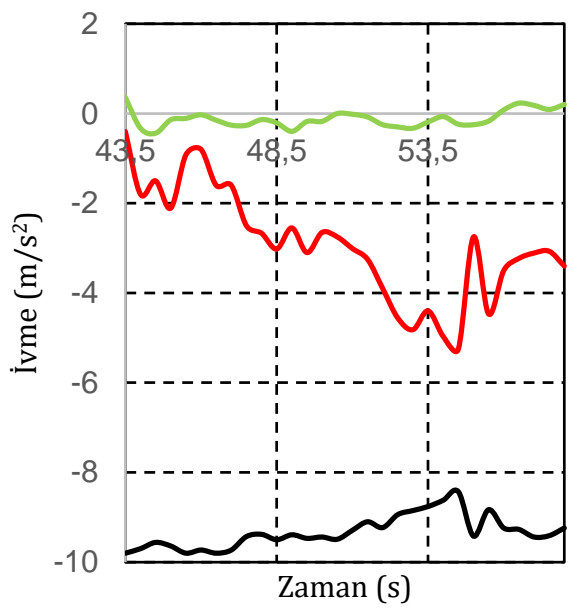

Şekil 11. $64 \mathrm{~km} / \mathrm{h}$ - 0km/h yavaşlama ivme ölçüm grafiği 
DEU FMD 21(62), 621-632, 2019

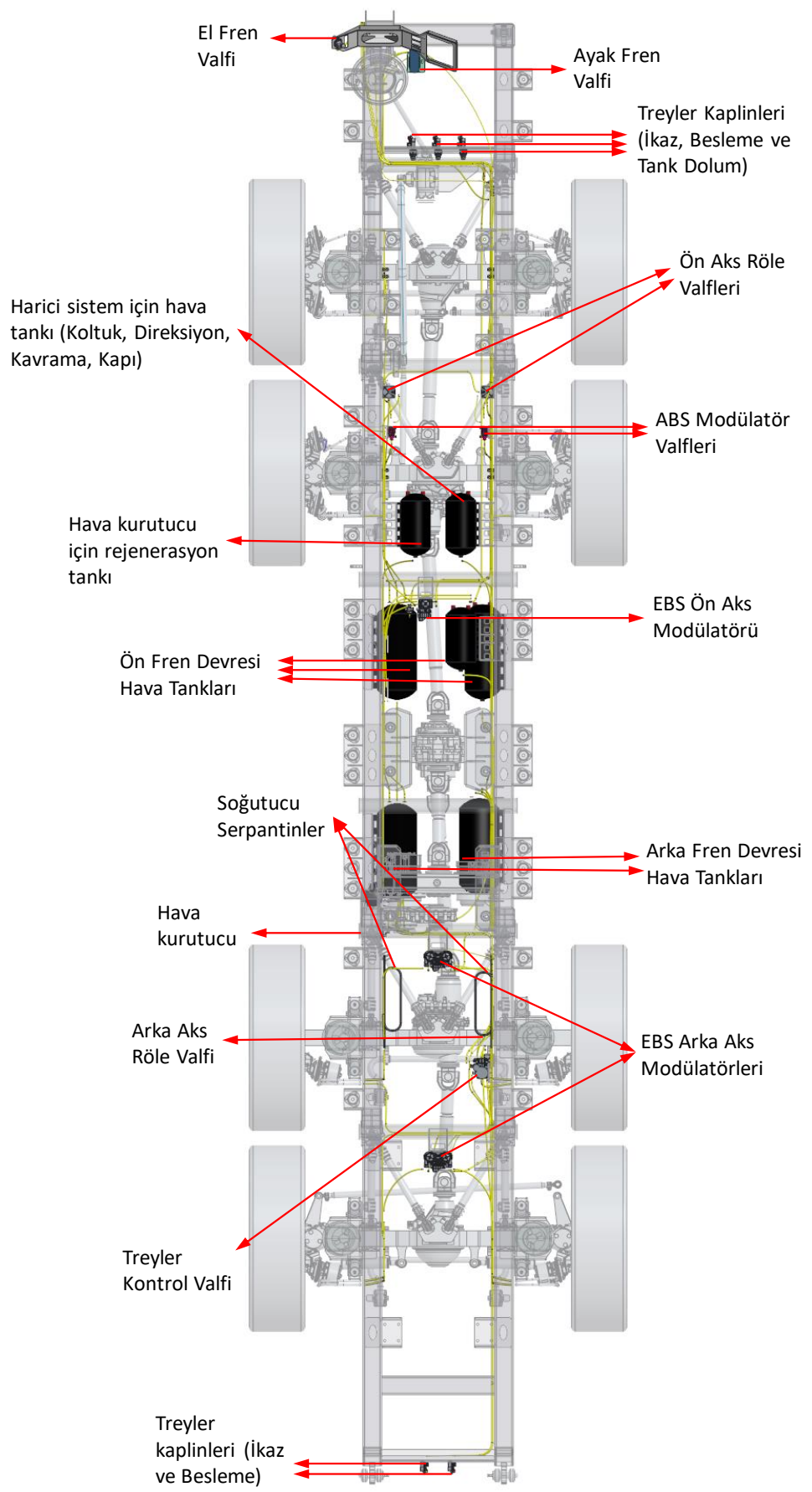

Şekil 12. Fren sistemi elemanlarının taşıt üzerinde yerleşimi 


\section{DEU FMD 21(62), 621-632, 2019}

\section{Tartışma ve Sonuç}

Bu çalışma neticesinde iki akstan daha fazla akslı taşıtlarda kullanılan fren sistemleri için tasarım ve uygulama örneği oluşturulmuştur. İki akstan daha fazla aks barındıran taşıtlara ait hesaplamalarda ortaya çlkan hiperstatik problem sorunu ortaya konan etkin aks açıklığ kavramı ile aks yüklerine bağlı parametrik bir ifade olarak ihtiyaç duyulan denklemlere entegre edilmiș ve güvenilir sonuçlar elde edilmiştir. Bunlara ek olarak hesaplamalarda söz edilmeyen ancak Şekil 12'de gösterilen ekipmanlar; ilgili standartlarda belirtildiği gibi taşıtın anti bloke fren sistemi (ABS) ile donatılması için gerekli olan elektro-pnömatik bileşenlerdir. $\mathrm{Bu}$ çalışma neticesinde, çok akslı bir ağır taşıtın fren sistemi tasarımı için uygulanacak yöntem ortaya konmuştur.

\section{Kaynakça}

[1] Kuralay, N.S. 2008. Motorlu Taşıtlar; Temel ve Tasarım Esasları, Yapı Elemanları, Cilt 1; Tahrik ve Sürüș Sistemleri. İzmir: TMMOB Makina Mühendisleri Odası, Yayın No: MMO/2008/484; 315s.

[2] Demirsoy, M., 2005. Motorlu Taşıtlar, Cilt 2. İstanbul: Birsen Yayınevi, ISBN:975-511-069-0.

[3] Hamurișçi, Y., Kuralay, N.S., Topaç, M.M. 2010. Ağı Ticari Taşıt Frenleri için Test Düzeneğinin Kavramsal Tasarımı. 5. Otomotiv Teknolojileri Kongresi,07-08 Haziran, Bursa.

[4] Bayrakçeken, H., Altıparmak, D. 2005. Mathematical Modeling and An Experimental Study for Vehicle Braking Force Analysis, G.Ü. Fen Bilimleri Dergisi, Cilt: 18(3), s. 489-503. ISSN: 1303-9709.

[5] XU, L., Zhang, J., Yan, X., Zhou, Z. 2016. Parameter Optimization of An Automobile Brake System Using A Novel Improved Genetic Algorithm, International Journal of Simulation Systems, Science \& Technology, Cilt: 17(46), s. 9.1-9.6. DOI: 10.5013/IJSSST.a.17.46.09.

[6] Esmailzadeh, E., Goodarzi, A., Behmadi, M. 2011. Optimized Braking Force Distribution during $A$ Braking-in-Turn Maneuver for Articulated Vehicles, International Journal of Automotive Engineering, Cilt:1(1), s. 56-61. DOI: 10.1109/ICMET.2010.5598422.

[7] He, L., Wang, X., Zhang, Y., Wu, J., Chen, L. 2011. Modeling and Simulation Vehicle Air Brake System. 8. Modelica Conference, 20-22 Mart, Dresden.

[8] Mithun, S., Mariappa, S., Gayakwad, S. 2014. Modeling and Simulation of Pneumatic Brake System Used in Heavy Commercial Vehicle, Journal of Mechanical and Civil Engineering, Cilt: 11(1), s. 1-9.

[9] He, L, Wu, J, Peng, M, Hou, Y, Chen, L. 2012 Modeling and Co-Simulation for Air Brake System of Heavy Truck, Advanced Materials Research, Cilt: 466-467, s. 1109-1114. DOI: 10.4028/AMR.466 467.1109.
[10] Düzgün, M., Altıparmak, D., Bayrakçeken, H. 2005. An Experimental Investigation of Stopping Distance of Automobiles, G.Ü. Fen Bilimleri Dergisi, Cilt: 18(1), s. 153-165. ISSN: 1303-9709.

[11] Bayrakçeken, H., Düzgün, M. 2005. Taşıtlarda Fren Verimi ve Frenleme Mesafesi Analizi. Politeknik Dergisi, Cilt:8, Sayı: 2, s. 153-160. ISSN: 1302-0900.

[12] Rossmann, E. 2004. Brake Design for Multi-Axle Vehicles. SIMPACK User Meeting Presentation.

[13] Ishak, M.R., Bakar, A.R., Belhocine, A., Taib, J.M., Omar, W.Z.W. 2016. Brake Torque Analysis of Fully Mechanical Parking Brake System: Theoretical and Experimental Approach. Measurement, Cilt: $94 \mathrm{~s}$. 487-497. DOI: 10.1016/j.measurement.2016.08.026

[14] Miraei, M., Mirzaeinejad, H. 2012. Optimal Design of A Non-Linear Controller for Anti-Lock Braking System. Transportation Research Par C, Cilt: 24, s. 19-35. DOI: 10.1016/j.trc.2012.01.008.

[15] Wang, C., Zhao, W., Li, W. 2018. Braking Sense Consistency Strategy of Electro-Hydraulic Composite Braking System. Mechanical Systems and Signal Processing, Cilt: 109, s. 196-219. DOI: 10.1016/j.ymssp.2018.02.047.

[16] Heisler, H. 2002. Advanced Vehicle Technology, Second Ed. Butterworth-Heinemann Publishing, ISBN: 0-7506-5131-8.

[17] Breuer, B., Dausend, U. 2003. Advanced Brake Technology. SAE International. ISBN: 0-7680-12473.

[18] Reif, K. 2014. Brakes, Brake Control and Driver Assistance Systems Function, Regulation and Components. Springer. ISBN: 978-3-658-03977-6.

[19] Nunney, M.J. 2007. Light and Heavy Vehicle Technology, Fourth Ed. Butterworth-Heinemann Publishing. ISBN: 0-7506-8037-7.

[20] Halderman, J.D. 2012. Automotive Technology Principles, Diagnosis and Service, Fourth Ed. Pearson Publishing, ISBN: 0-13-254261-7. 